\title{
Tecnologias de informação e comunicação no ensino de psicologia para educadores: reflexões
}

\author{
Rita de Cássia Vieira \\ Daniela Marx Damascena \\ Universidade Federal dos Vales do Jequitinhonha e Mucuri
}

\section{Resumo}

Este texto apresenta ponderações sobre o ensino de psicologia para educadores e baseou-se num projeto de ensino e pesquisa desenvolvido no âmbito da disciplina Psicologia da Educação, ministrada no Bacharelado em Humanidades da Universidade Federal dos Vales do Jequitinhonha e Mucuri (UFVJM), Minas Gerais. O objetivo central da proposta foi o de conjugar o uso de diferentes tecnologias digitais para potencializar o processo de ensino-aprendizagem do conteúdo programático da disciplina. Priorizou-se no processo o binômio teoriaprática e o AVA Moodle foi de fundamental importância para a concretização dos objetivos propostos. Os dados foram colhidos a partir de entrevistas individuais semiestruturadas e analisados com o suporte da perspectiva fenomenológicocompreensiva de pesquisa. Dentre os resultados alcançados, destaca-se o fato de que a inclusão digital ainda se encontra longe de se tornar realidade para determinadas regiões e segmentos da população brasileira, constatação que tem implicações na inclusão escolar e social dos sujeitos estudados.

Palavras-chave: Ensino de psicologia. Formação de professores. Novas tecnologias. Inclusão digital e social. 


\section{Information and communication technologies in psychology's teachers training: reflections}

This paper presents considerations about the teaching of psychology for educators and was based on a teaching-research project developed within the discipline Psicologia da Educação, taught in the Bachelor of Humanities, at Federal University of Jequitinhonha and Mucuri Valeys (Universidade Federal dos Vales do Jequitinhonha e Mucuri, UFVJM), Estate of Minas Gerais, Brazil. The main objective of the proposal was to combine the use of different digital technologies to enhance the teachinglearning process during the course. Theory and practice are both prioritized in the process and the Moodle VLE was fundamental for achieving the objectives. Data were collected from semi-structured individual interviews and analyzed with the support of the phenomenological-comprehensive research perspective. Among the results achieved, there is the fact that digital inclusion is still far from becoming reality for some regions and segments of the population, finding that has implications for educational and social inclusion of the subjects studied.

Keywords: Psychology's teaching. Teacher training. New Technologies. Digital and social inclusion. 


\section{Tecnologías de la información y la comunicación en la enseñanza de la psicología para los educadores: reflexiones}

Este artículo presenta consideraciones acerca de la enseñanza de la psicología para los educadores y se basó en un proyecto docente e investigadora desarrollada dentro de la disciplina de psicología de la educación que se imparte en la Licenciatura de Humanidades en la Universidade Federal dos Vales do Jequitinhonha e Mucuri, UFVJM, Minas Gerais . El principal objetivo de la propuesta era combinar el uso de diferentes tecnologías digitales para mejorar el proceso de enseñanza-aprendizaje del plan de estudios del curso. Fue dado prioridad en el proceso el binomio teoríapráctica y el Moodle VLE fue de fundamental importancia para el logro de los objetivos. Los datos se obtuvieron de entrevistas individuales semiestructuradas y analizados con el apoyo de la perspectiva de la investigación fenomenológicacompreensiva. Entre los resultados obtenidos, se encuentra el hecho de que la inclusión digital aún está lejos de convertirse en realidad para algunas regiones y sectores de la población, hallazgo que tiene implicaciones para la inclusión educativa y social de los sujetos estudiados.

Palabras-clave: Psicología de la enseñanza. Formación docente. Nuevas tecnologías. Inclusión digital y social. 


\section{Introdução}

O debate atual sobre educação e escola se inscreve em um contexto de importantes e provocadoras transformações sociais, especialmente enfatizadas pelos processos desencadeados pela globalização. Para Tardif e Lessard (2005), o magistério constitui-se numa dimensão central para se entender estas transformações e deve ser tratado como uma ocupação fundamental nas sociedades contemporâneas.

É neste cenário de complexidade, mudanças e desafios que este texto pretende destacar a psicologia. Sendo um dos campos do saber humano que contribuem na compreensão e encaminhamento do fenômeno educativo, a psicologia ocupou - e ocupa ainda hoje - um lugar de relevância na educação. As disciplinas denominadas "Psicologia da Educação" e afins ${ }^{1}$, historicamente, integram as estruturas curriculares dos cursos de formação de professores. Seus conteúdos são considerados saberes indispensáveis à prática educativa e ocupam lugares de destaque nos currículos das licenciaturas e da pedagogia. Essas disciplinas guardam, ainda, a característica de se constituírem em fundamentais espaços de interlocução entre os campos disciplinares da psicologia e da educação.

Nessa perspectiva, investigações sobre a formação de professores para atuar na educação básica têm sido numerosas e vêm cada vez mais ganhando destaque no domínio da pesquisa educacional brasileira. Múltiplos aspectos sobre essa temática têm sido estudados e revelam a necessidade cada vez mais premente de se construir alternativas para esse campo. Tais estudos afirmam a urgência de mudanças e sinalizam com caminhos para a construção de processos formativos que assegurem uma sólida formação teórica interdisciplinar, contextualizada e implicada com as demandas e reais necessidades sociais brasileiras. Aliás, trabalhos não muito recentes já apontavam as dificuldades dos cursos de licenciatura em atingir os objetivos formativos a eles atribuídos (Candau, 1987; Braga, 1988; Alves, 1992; Marques, 1992).

A despeito desta situação, uma questão que vem surgindo para essa interface na atualidade tem sido o questionamento acerca da real efetividade desse diálogo no cotidiano daqueles que se encontram nos contextos escolares/educativos. Neste debate, alguns estudos como, por exemplo, os de Bergamo e Romanowski (2006), Almeida et al. (2007) e Lucion e Frota (2009) chamam a atenção para o fato de que o ensino dessas disciplinas nesses cursos é, na maioria das vezes, pouco eficiente e não contribui para uma intervenção efetiva em sala de aula. Nessa direção, e tendo como foco contribuir com a discussão, recentemente (Vieira, Assis; Campos, 2013) tivemos a oportunidade de chamar a atenção para a necessidade de se pensar numa

1 Tal qual em trabalho anterior (Vieira, Figueiredo, Souza e Fenner, 2013), consideram-se "disciplinas afins à Psicologia da Educação" aquelas que tratam de conteúdos relacionados à interface Psicologia e Educação. Nesse grupo, incluem-se disciplinas correlatas ao campo em questão, como, por exemplo, as "Psicologias do desenvolvimento", etc. 
revisão dos conteúdos ministrados e dos recursos metodológicos utilizados no encaminhamento das disciplinas "Psicologia da Educação".

Dada a importância desse lugar que vem sendo ocupado pela psicologia na formação docente é que se tornam bem-vindas discussões e buscas de alternativas que visem potencializar a qualidade de sua inserção nesses cursos. Este artigo visa, assim, apresentar sua contribuição a este debate e tem por base um projeto de ensino e pesquisa desenvolvido no curso de Humanidades da Universidade Federal dos Vales do Jequitinhonha e Mucuri (UFVJM), no campus de Diamantina, em Minas Gerais. A proposta, denominada "Novas tecnologias no ensino de psicologia para futuros professores", foi desenvolvida no $2^{\circ}$.semestre de 2014 e no $1^{\circ}$. semestre de 2015, respectivamente, e teve como objetivo central introduzir e conjugar o uso de diferentes tecnologias digitais visando potencializar o processo de ensinoaprendizagem dos conteúdos desenvolvidos na disciplina Psicologia da Educação, obrigatória na grade curricular do curso de pedagogia e das licenciaturas oferecidas pela Universidade 2 .

\section{A psicologia e a formação docente na atualidade}

Há um consenso acerca das transformações pelas quais vêm passando as sociedades modernas. Mudanças nos âmbitos social, político, econômico e cultural invadem o dia a dia de todos sem que se tenha tempo para analisá-las e refletir sobre como agir concretamente diante dos desafios que delas decorrem. No âmbito da educação, este quadro não é diferente, assim como não o é também na psicologia da educação, um campo do saber humano que se apresenta ainda intricado e desafiante por tratar simultaneamente de duas dimensões por si só complexas: a psicológica e a educativa.

A psicologia se destaca como um dos campos do saber humano que pode contribuir substantivamente na compreensão e encaminhamento do fenômeno educativo. O vínculo entre essas duas disciplinas - psicologia e educação - encontra-se consolidado e permanece em franco desenvolvimento. A psicologia ocupou - e ocupa ainda hoje - um lugar de relevância na educação e, numa análise mais específica, as disciplinas denominadas "Psicologia da Educação" e afins historicamente integram as estruturas curriculares dos cursos de formação de professores. Seus conteúdos tem sido considerados saberes indispensáveis à prática educativa e possuem lugar de destaque nos currículos das licenciaturas e da pedagogia. Além disso, essas disciplinas guardam ainda a característica de se constituírem em fundamentais espaços de interlocução entre esses dois campos do saber. Esse diálogo, apesar

O curso de Humanidades (UFVJM, 2011) oferece uma formação sequencial que serve de base para a Pedagogia e as Licenciaturas ofertadas na Universidade - Geografia, História, Letras (Espanhol/Inglês). 
de seus limites, dificuldades, contradições e percalços, vem ocorrendo de forma produtiva e crescente. Os estudiosos dessa interface continuam investigando e refletindo sobre velhas e novas questões e a produção tem se revelado extensa e rica.

Formar professores para atuar na educação básica é tema central de debate na educação brasileira. Inúmeras análises (a exemplo de Souza, 2007 e Gatti, 2010, dentre outras), reafirmam os problemas crônicos nos cursos de pedagogia e nas licenciaturas. Por outro lado, há também um entendimento crescente de que o exercício da docência vem se tornando cada vez mais complexo e mais desafiador. Sendo um trabalhador da contradição (Charlot, 2008), o professor enfrenta em sala de aula situações que decorrem da configuração econômica, social e cultural vivenciada na atualidade e que traz em si interrogações de vulto para aqueles que se dedicam à educação. Assim, formar educadores para atuar na educação básica com sólida fundamentação em conhecimentos acadêmicos que os habilitem a construir um olhar contextualizado sobre a escola, o sistema educacional e a realidade social mais ampla na qual se encontram inseridos é hoje um dos grandes desafios da educação brasileira.

Uma significativa e consolidada produção teórica alerta que os problemas vividos no enfrentamento desse desafio são inúmeros, de ordem conjuntural e excedem os próprios limites dos cursos de formação acadêmica (Marques; Diniz-Pereira, 2002). A baixa ocupação de vagas nos cursos já existentes, o desestímulo dos jovens para escolher o magistério devido à precariedade global da profissão (más condições de trabalho, salários pouco atraentes, jornada de trabalho excessiva, inexistência de planos de carreira, precariedade dos processos escolares, etc.) e o declínio do status social da docência "fazem com que os cursos de licenciatura, tanto em instituições públicas como privadas, vivam em constante crise" (Marques; Diniz-Pereira, 2002, p.175).

No campo da psicologia, esse desafio toma proporções ainda maiores, pois a temática relativa à formação de professores é pouco estudada e ainda não existe um conhecimento consolidado a esse respeito. Acrescente-se a esse quadro o fato de que raras são as investigações que privilegiam compreender essa problemática, considerando a natureza social, cultural e histórica do fenômeno educativo (Carvalho, 2003; Silva, Facci, Silva, 2008).

Atuando desde o ano de 2008 como docente de disciplinas que trabalham conteúdos de psicologia, em sua maioria densos e abstratos, venho desde então buscando alternativas didáticas que me permitissem aproximar estes conteúdos da realidade concreta dos graduandos. Tanto em cursos de psicologia (Vieira e outr os, 2013) quanto nos de pedagogia e licenciaturas, foi possível perceber que a problemática relativa à formação não se diferenciava e dizia, em resumo, de uma incapacidade dos profissionais, ao se inserirem no mercado de trabalho, para estabelecer relações 
entre suas vivências profissionais cotidianas e o conhecimento teórico que havia sido adquirido em seus cursos de graduação.

A cada dia, acentuava-se a ideia de que a psicologia precisava ser ensinada como um corpo de saberes vinculado aos problemas reais dos alunos. Nas palavras de Raposo e Maciel (2006), a psicologia precisa

[...] partir das questões educacionais, tornando-as objeto de investigação, e analisá-las nas perspectivas dos conteúdos e métodos psicológicos, com foco no retorno ao ponto de partida, que é, afinal, a prática educativa. Tais disciplinas devem reunir psicologia e educação em unidades dialéticas de ação e reflexão que se personificarão nas decisões do professor para favorecer e direcionar o desenvolvimento e a aprendizagem do aluno. Traduzir-se-á em atividade concreta e inteligente do professor permitindo e impulsionando a relação teoria e prática. (Raposo; Maciel, 2006, p. 5)

Também Larocca ( 2000, 2002, 2007), ao defender a indissociabilidade entre teoria e prática, aposta nesse viés como fundamental para a formação de profissionais críticos, sujeitos de seu pensar e agir, capazes de compreender o alcance de sua futura condição à frente de uma sala de aula.

Nesse sentido, o exercício pessoal da docência alicerçou ainda mais algumas reflexões relativas ao ensino de psicologia em cursos de formação de professores. Dentre elas, duas se destacaram e se constituíram no ponto de partida para a proposta que ora se apresenta: como integrar os conteúdos de psicologia a outros saberes, de forma a tornar o seu ensino mais instrumental aos futuros professores? De que maneira ela poderia contribuir para facilitar a vivência cotidiana nos futuros contextos de trabalho destes professores em formação?

$\mathrm{Na}$ tentativa de responder a estas indagações, as tecnologias de informação e comunicação, as TICs, apresentaram-se como aliadas na condução do processo em questão. Minha experiência anterior em EaD já havia apontado que elas poderiam facilitar o acesso aos temas tratados sob outras e diferentes óticas, favorecendo, de forma mais amena, - mas nem por isso menos crítica e aprofundada - um trabalho interdisciplinar e dialético no contexto da sala de aula.

Incluir na proposta aqui em discussão a utilização de TICs era, portanto, uma opção em consonância com a crescente digitalização do mundo moderno. Em praticamente todos os espaços da vida contemporânea, uma das habilidades mais demandadas tem sido a do uso dessas tecnologias, "resultado da fusão de três grandes vertentes técnicas: a informática, as telecomunicações e as mídias eletrônicas" (Belloni, 2005, p.21). Ainda que não sejam a solução para muitas das questões que interferem no processo de ensino-aprendizagem, para aquele professor que faz uma apropriação crítica desses recursos, as TICs podem se configurar em instrumentos fundamentais de provocação dos alunos, instigando-os na busca do conhecimento. 
Essas ferramentas tecnológicas se encontram cada vez mais presentes no cenário educacional e sua utilização contextualizada ainda é um desafio para a educação nos dias de hoje. Coll, Mauri e Onrubia (2010) destacam a potencialidade desses recursos. Contudo, estes autores advertem para o uso ainda limitado dos mesmos em sala de aula e observam que

as TICs em geral e a internet, em particular, ainda são pouco utilizadas - pouquíssimo, na maioria das salas de aula - e que, quando utilizadas, tanto pelos professores quanto pelos alunos, com frequência é para se fazer o que já se fazia sem elas [...]. (Coll, Mauri, Onrubia, 2010, p. 87)

Confirmando esta assertiva, um estudo brasileiro (Champangnatte; Nunes, 2011) mostra que, embora o uso destes recursos seja considerado importante pela maioria dos professores, ainda o fazem de maneira ainda incipiente e ilustrativa em suas atividades.

Além disso, Coll, Mauri e Onrubia (2010) deixam claro que a potencialidade dessas ferramentas pode ou não tornar-se uma realidade efetiva. Assim, as TICs podem tornar mais eficientes e produtivos os processos de ensino e aprendizagem, desde que se transponham alguns desafios. Dentre eles, estes estudiosos ressaltam a necessidade de se cobrirem as carências relacionadas à infraestrutura e equipamentos, que continuam sendo muito significativos em vários países.

Desta forma, tendo essa perspectiva em vista, procurou-se, num primeiro momento, manter um olhar apurado sobre como os alunos matriculados na disciplina Psicologia da Educação se relacionavam com as tecnologias digitais. Foram propostas atividades onde os mesmos teriam que, obrigatoriamente, recorrer a elas para desenvolver a contento o que foi solicitado e, a partir daí, observou-se a pouca intimidade da maioria dos discentes com os recursos demandados para o desenvolvimento das tarefas. Alguns, ainda que em menor número, mostraram dificuldade até mesmo para realizar atividades mais simples como, por exemplo, acessar e-mails, baixar, converter e imprimir arquivos. Numa enquete informal, também relataram pouca familiaridade com a utilização da plataforma virtual de aprendizagem Moodle. Com base na constatação desse quadro é que se deu o desenvolvimento da proposta que ora se discute e que comporta um duplo desafio, como se verá mais adiante.

\section{Método}

A proposta de ensino girou em torno do privilégio ao binômio teoria-prática. Além de buscar o auxílio das TICs para potencializar o processo de ensino e aprendizagem dos conteúdos psicológicos trabalhados na disciplina, intencionava-se também desenvolver nos alunos habilidades que lhes permitissem lidar de forma crítica com 
estes recursos no âmbito acadêmico. Desta forma, esta instrumentalização poderia ser estendida à futura atividade docente dos mesmos.

Com isto, no decorrer das aulas buscou-se aliar o ensino dos conteúdos com algumas das tecnologias atualmente utilizadas no âmbito educacional. Uma das ferramentas preferenciais de suporte para o desenvolvimento do curso foi o AVA Moodle, assim como seus recursos tecnológicos (fóruns, wikis, chats, blogs, etc.). Essa plataforma foi amplamente utilizada para a realização de atividades, para a disponibilização de materiais didáticos (vídeos, textos, slides, referências, etc.) e, ainda para orientação, acompanhamento e avaliação - em processo e final - da proposta.

Sendo simultaneamente um projeto de ensino e pesquisa, a coleta dos dados foi realizada no segundo semestre letivo de 2014 por meio de entrevistas individuais semiestruturadas (gravadas e transcritas literalmente) com dois estudantes regularmente matriculados na licenciatura em Letras e frequentes na disciplina em questão. Aos entrevistados, escolhidos de forma aleatória dentre os que se dispuseram e se interessaram em participar do estudo, foi disponibilizado o Termo de Consentimento Livre e Esclarecido (TCLE). As entrevistas seguiram um roteiro prévio que privilegiou os seguintes temas: interesse pelo uso de TICs na educação; contribuições das TICs para a educação; dificuldades e desafios na utilização das TICs; utilização das TICs (tipos e usos); uso das TICs na disciplina em curso (interesses, desafios, contribuições ao processo de ensino e aprendizagem, sugestões). Os dados coletados foram analisados a partir de uma orientação fenomenológica.

O método fenomenológico de fazer pesquisa não é um método explicativo, mas de descrição, de compreensão, onde se procura captar a intencionalidade do objeto pesquisado. A perspectiva aqui é de que a realidade sempre é percebida com um significado que lhe é atribuído - o vivido - e, sendo assim, a pesquisa fenomenológica vai tentar penetrar nesse significado, buscando desvelar aquilo que se encontra oculto por detrás dos dados levantados numa investigação, aquilo que não aparece imediatamente, ou seja, buscando ir além do nível explicativo.

Acentralidade dessa postura - influenciada pelas proposições de Husserl(1897/2002) - reside na busca por se captar a intencionalidade, o significado atribuído pelo sujeito a um determinado objeto, elucidando as relações entre a experiência direta vivida por esse sujeito e o significado que essa experiência tem para o mesmo. Tal experiência, além de possuir um componente perceptivo e um afetivo, comporta ainda uma terceira dimensão, a intelectiva, caracterizada pela elaboração em si, pela crítica, pelo juízo emitido a partir de uma determinada vivência. Esse aspecto é de fundamental relevância ao se observar que o conhecimento de algo que nos é externo implica no autoconhecimento, ou seja, o objeto da experiência não é somente o fenômeno, mas também o próprio sujeito, que emerge da experiência e também está presente nela. Não existe apenas o sujeito da experiência, mas um ser que, ao conhecer, também se revela na experiência (Giovanetti, 1999, 2000; 
Mafhoud, 1999; Wojtyla, 1982).

$\mathrm{Na}$ pesquisa aqui apresentada, seguiu-se uma estrutura de passos proposta por Amatuzzi. Com base nas orientações centrais da fenomenologia, este autor sugere um formato de investigação que consiste numa análise psicológica de vivências, um estudo de experiências específicas e situadas Amatuzzi (1996, 2001a, 2001b, 2006, 2009). Parte-se de uma delimitação precisa do objeto de estudo para um encontro com o fenômeno e sua alteridade em termos concretos, passando por momentos onde os depoimentos são lidos, revistos, analisados - em partes e no todo - e, finalmente, articulados e interpretados. Nesse percurso, há uma busca incessante para compreender a totalidade do vivido, com vistas a se chegar a uma descrição consistente e aprofundada do fenômeno estudado.

Dentro dessa perspectiva, os significados explicitados pelos entrevistados, compuseram uma estrutura organizada de vivências que, articuladas, serão objeto de descrição e análise a seguir.

\section{Resultados e discussão}

Apesar de contar praticamente uma década, a UFVJM já existia desde os anos de 1950. Fundada em 30 de setembro de 1953 por Juscelino Kubitschek de Oliveira e federalizada em 17 de dezembro de 1960, a Faculdade Federal de Odontologia de Diamantina (Fafeod) transformou-se em Faculdades Federais Integradas de Diamantina (Fafeid) em 04 de outubro de 2002, que foram elevadas à condição de Universidade Federal dos Vales do Jequitinhonha e Mucuri (UFVJM) em 06 de setembro de 2005, tendo sido publicada a transformação no Diário Oficial da União em 08 de setembro de 2005, pela Lei $n^{\circ} 11.173$, de 06 de setembro de $2005^{3}$.

A partir daí, integrando o REUNI ${ }^{4}$, a UFVJM assume a incumbência de suprir lacunas regionais no que se refere à igualdade de oportunidades de acesso à educação superior. No caso dos cursos de licenciatura, esse papel tem sido cumprido, já que $74 \%$ dos estudantes desses cursos são oriundos das regiões englobadas pelos Vales (Soares, 2014). Neste contexto, apresenta-se o Bacharelado Interdisciplinar

3 Dados extraídos do site oficial da Universidade e disponíveis em: http://www.ufvjm.edu.br/universidade/historia. html?lang=pt_BR.utf8\%2C+pt_BR.UT

4 O REUNI - Programa de Apoio a Planos de Reestruturação e Expansão das Universidades Federais - foi instituído pelo Governo Federal por meio do Decreto n 6.096 de 24 de abril de 2007 . Seu objetivo é o de criar condições para ampliação do acesso e permanência na educação superior, no nível de graduação, para o aumento da qualidade dos cursos e melhor aproveitamento da estrutura física e de recursos humanos existentes nas Universidades Federais, respeitadas as características particulares de cada instituição e estimulada a diversidade do sistema de ensino superior. 
em Humanidades, etapa inicial das licenciaturas ofertadas na Universidade, que se insere numa categoria de cursos que, de acordo com o Parecer CNE/CES $n^{\circ}$ 266/211, devem ser vistos "como uma nova opção de formação acadêmica dissociada dos formatos convencionais, com foco nos fundamentos da produção científica e tecnológica contemporâneos" (Parecer CNE/CES n² 266/211, p. 3).

$\mathrm{Na}$ esfera governamental, observa-se que existe um consenso sobre a importância de se formar estudantes capazes de utilizar com desenvoltura as novas tecnologias, base para diversas atividades profissionais na contemporaneidade. Além do Parecer acima referido e outros documentos oficiais regulatórios, vale citar ainda os Referenciais Orientadores para os Bacharelados Interdisciplinares e Similares (2010). Estes indicam, entre as principais características esperadas para um diplomado em curso superior, a necessidade de "possuir largo espectro de competências genéricas em variados campos do conhecimento, especialmente das novas tecnologias, que formam a base das diversas competências profissionais" (Referenciais Orientadores para os Bacharelados Interdisciplinares e Similares, 2010, p. 5).

Nessa direção, a incorporação das tecnologias de informação e comunicação na educação tem sido tema de inesgotável discussão neste âmbito. Para Coll, Mauri e Onrubia (2010) existe nesse meio a atribuição de um potencial transformador e inovador a estes recursos que pode ou não se concretizar em função dos contextos de uso das mesmas. Esses autores apontam que

São, portanto, os contextos de uso - e no marco desses contextos, a finalidade ou finalidades perseguidas com a incorporação das TIC e os usos efetivos que professores e alunos venham a fazer dessas tecnologias em escolas e salas de aula - que acabam determinando seu maior ou menor impacto nas práticas educacionais e sua maior ou menor capacidade para transformar o ensino e melhorar a aprendizagem. (Coll, Mauri, Onrubia, 2010, p. 66-67)

Para os entrevistados, existe um interesse real no aprendizado de novas tecnologias e no seu uso, como se pode comprovar nas falas que se seguem: "Eu acho que principalmente nessa matéria ta sendo muito bom; você estudar psicologia que é difícil da gente entender e ainda ter que usar o Moodle eu estou gostando muito [...]" (Carla ${ }^{5}$. "Eu acho que a internet, o Moodle, ajudam muito a gente aqui na faculdade" (Antônio).

No entanto, esses mesmos estudantes trazem à discussão aspectos que remetem às colocações apresentadas por Coll, Mauri e Onrubia (2010). Assim, para estes futuros professores, parece bem evidente a necessidade de se discutir os contextos de uso desses recursos, tanto no momento do em que ocorrem seus próprios processos de ensino-aprendizagem, quanto em momentos futuros. Carla, na época da entrevista, uma estagiária numa escola de ensino médio, exemplifica isto em sua fala:

5 Nomes fictícios. 
Aprender aqui do jeito que a gente vem aprendendo é bom; como eu disse [...] facilita muito, mas pra gente não é muito fácil não porque a internet aqui é lenta. Eu não tenho muito tempo não por causa de trabalho e lá na minha cidade (Gouveia) a internet é muito ruim, é muito lenta, cai toda hora, então num dá pra gente ficar dependendo dela. Você imagina isso também em sala de aula, porque aqui na universidade é melhor o acesso, mas na escola onde eu estou [...] minha nossa [...] se eu fosse professora lá eu acho que nem ia pensar nisso por enquanto [...] (Carla)

Este relato traz à tona o tema da inclusão digital, um debate vigente com o Plano Nacional de Banda Larga (PNBL), uma tentativa de reduzir o atraso brasileiro em relação a outros países onde essa política foi implementada. Em sua versão mais recente, o PNBL se propõe a oferecer internet de alta velocidade a toda a população a baixos custos, tendo como pressuposto a ideia de que o acesso à internet configurase como um valor fundamental para o desenvolvimento social, econômico e cultural do país (Lemos, 2011). Esse autor enfatiza o desafio da inclusão digital no país quando adverte que

o lobby das empresas de telecomunicação e das operadoras de internet que dominam o mercado no país está colocando limites muito concretos ao sucesso do empreendimento. O custo sugerido pelo governo é de $R \$ 35,00 / \mathrm{m}$ para uma velocidade de $1 \mathrm{Mbps}$, mas a mesma vai diminuindo quando o consumo passa de $300 \mathrm{Mb}$ a $500 \mathrm{Mb}$, a depender da operadora, fazendo com que o usuário tenha duas opções: ou pague mais, ou use a internet com velocidade reduzida. Ouvir música, ver filmes ou vídeos, ou mesmo baixar e atualizar programas na máquina estão, nesse modelo, inviabilizados. (Lemos, 2011, p. 15)

Quando segue afirmando que "o PNBL, se assim se constituir, será um projeto que visa incluir, mas que na realidade exclui os já excluídos, dando a eles um falso sentimento de inclusão", este mesmo autor (Lemos, 2011, p. 15) apenas confirma o que já foi exposto pelos entrevistados quando os mesmos vinculam interesses e contribuições oferecidas pelas TICs à educação com as condições de acesso e operacionalidade vividas na região. Quando indagada acerca de seu interesse no uso de TICs na educação - tanto como atual aluna quanto como futura professora -, Carla afirma que "é mais ou menos" e prossegue enumerando as dificuldades encontradas no trato com essas e a internet. Assim, lentidão, instabilidade, dificuldade de acesso, aliam-se a outros desafios como o trabalho diário e o deslocamentos até a Universidade como fatores de desestímulo ao uso dos recursos tecnológicos.

Os entrevistados mostraram interesse pela didática desenvolvida no decorrer do semestre. Apresentar conteúdos psicológicos em diálogo com algumas das mais recentes tecnologias à disposição da educação foi visto, respectivamente por Carla e Antônio, como "diferente" e "estimulador" (sic). Sentiram-se motivados a aprender a lidar com os recursos do Moodle e outros, até porque, como observa Antônio "outros professores também usam [...] tem professor que dá até prova" no ambiente, 
apontando para a tentativa de fomento ao uso de recursos tecnológicos realizada por alguns docentes. No entanto, as dificuldades operacionais já apresentadas voltam a interferir também nesse aspecto. Carla narrou que, em determinado momento, pensou até em desistir de realizar uma atividade solicitada e só não o fez porque parou, descansou, e voltou ao computador outra vez, já mais tarde, quando "enfim consegui uma hora que deu tudo certo, a internet tava boa e eu acabei de fazer o exercício que a professora pediu".

A despeito das dificuldades encontradas no percurso, pode-se dizer que foi válida a proposta de relacionar os conteúdos teóricos da psicologia com a prática e ainda em articulação com as tecnologias, como se pode ver no relato de Antônio:

eu achei bom que a professora explicou, ensinou como a gente faz, mas a gente não tem tempo de praticar, não tem muita condição, né?... (condição de que?)... ah, de tudo, viu? (explique melhor). Por exemplo, quando fui fazer aquela experiência do Piaget, foi muito complicado pra conseguir encaixar no meu tempo, mas quando eu fiz eu achei bacana porque deu pra ver direitinho quando a gente faz o que ele fala... aí a gente vê que é tudo verdade. (Antônio)

Sobre a inter-relação entre a teoria e a prática, vê-se que o compromisso da psicologia com educação vai muito além de um simples dialogar e só pode se concretizar por completo na ação e reflexão dos educadores. Ao se tornarem sujeitos críticos de seu pensar e seu agir - conquista que pode receber uma substancial contribuição da psicologia - os educadores estariam em aptos para replicar essa condição com os seus educandos. Não é, portanto, uma simples relação de causa e efeito. Trata-se de oferecer ao educador condições de se implicar, de desenvolver recursos subjetivos que o capacitem a uma prática pedagógica contextualizada, implicada do ponto de vista sociocultural. Uma prática levada adiante por sujeitos que pensam, sentem e agem criticamente e em consonância com a sua realidade (Larocca, 2002; Raposo, Maciel, 2006).

Questionados sobre outros aspectos relativos à formação e aprendizado como, por exemplo, sobre o fato de uma possível instrumentalização no uso de tecnologias de informação e comunicação se configurar como um diferencial no campo da profissão docente, mais uma vez os entrevistados colocam a perspectiva de melhoria das condições operacionais - a inclusão digital - como fator necessário para tal. Acrescente-se a isto o mencionado desconhecimento com relação às potencialidades das TICs, presente no cotidiano de docentes e estudantes em geral (Coll; Monereo, 2010; Bonilla; Pretto, 2011).

Castells (2002, citado por Lemos, 2011) chama a grande maioria dos que lidam com as tecnologias de "interagidos" e não "interagentes". Para ele, os interagido são aqueles que utilizam de forma precária e rudimentar os dispositivos e as redes eletrônicas, não sabendo tirar proveito de todos os benefícios culturais, sociais e 
econômicos que estes recursos oferecem. É, portanto, para os "interagidos" que os projetos de inclusão digital devem ser fortalecidos nas dimensões educacional e da cidadania. Esse, como observa Lemos (2011, p. 19) "é o desafio, não apenas brasileiro, mas mundial".

\section{Considerações finais}

A pesquisa evidenciou questões que vêm sendo debatidas no âmbito do ensino de psicologia para educadores, especialmente no eixo da educação básica. A indiscutível necessidade de se promover um diálogo efetivo entre as dimensões teóricas e práticas do processo de ensino e aprendizagem de conteúdos psicológicos é uma delas e remete, por sua vez, a uma necessária reflexão acerca dos recursos metodológicos utilizados. Estes devem ser capazes de possibilitar aos futuros docentes a articulação desses conteúdos vistos em sala de aula com suas experiências concretas vividas nos espaços educativos/escolares, buscando aproximar, o máximo possível, a teoria do fazer cotidiano desses futuros profissionais da educação.

A incorporação de tecnologias de informação e comunicação ao processo educativo ainda se configura como uma possibilidade, um desafio, não só para educadores, mas também para os educandos. De acordo com estudiosos da temática, essa introdução ainda é precária e sua utilização limitada, pois os principais envolvidos nesse processo - docentes e estudantes - ainda não se encontram preparados para fazer com que essas tecnologias ultrapassem o campo da potencialidade e se apresentem como verdadeiros recursos, capazes de provocar transformações reais no processo de ensino-aprendizagem.

Partindo dessa perspectiva, evidencia-se mais um desafio essencial para governantes e para a educação brasileira, que é o de promover a inclusão digital para boa parte da população. Integrante de uma inclusão social ampliada, a inclusão digital pode auxiliar aqueles que ensinam psicologia para educadores a alcançar sua mais instigante meta: a de formar sujeitos que pensam, sentem e agem criticamente e em consonância com a sua realidade. Educadores protagonistas de sua ação no mundo, munidos de recursos subjetivos que o capacitem a uma prática pedagógica contextualizada, implicada do ponto de vista social e cultural. Isto, provavelmente, poderá fazer a diferença no sentido de transformar realidades pessoais e profissionais. 


\section{Referências}

ALMEIDA, Rúbia Sousa; ALVES, Cândida Beatriz; NEVES, Gabriella Nunes; SILVA, Ludmila Pereira; PEDROZA, Regina Lúcia Sucupira. O professor de ensino médio e a psicologia em seu cotidiano escolar. Psicologia Escolar e Educacional, v.11, Campinas, jun/2007.

ALVES, Nilda (Org). Formação de professores: pensar e fazer. São Paulo: Ed Cortez, 1992.

AMATUZZI, Mauro Martins. Apontamentos acerca da pesquisa fenomenológica. Estudos de Psicologia, Campinas, v. 13, n. 1, 1996, p. 5-10.

AMATUZZI, Mauro Martins. Pesquisa do vivido. AMATUZZI, Mauro Martins. Por uma psicologia humana. Campinas: Ed. Alínea, 2001a, p. 53-60.

AMATUZZI, Mauro Martins. Pesquisa fenomenológica em Psicologia. BRUNS, Maria Alves de Toledo; HOLANDA, Adriano Furtado. Psicologia e pesquisa fenomenológica - reflexões e perspectivas. São Paulo: Omega Editora, 2001b.

AMATUZZI, Mauro Martins. A subjetividade e sua pesquisa. Memorandum, v. 10, p. 93-97, 2006. Disponível em: <http://www.fafich.ufmg.br/ memorandum/a10/ amatuzzi03.htm>. Acesso em: 25 jul. 2011.

AMATUZZI, Mauro Martins. Psicologia fenomenológica: uma aproximação teórica humanista. Estudos de Psicologia (Campinas), Campinas, v. 26, n.1, p.93-100, jan./ mar, 2009.

BELLONI, Maria Luiza. O que é mídia-educação. Campinas, SP: Autores Associados, 2005.

BERGAMO, Regiane Banzatto; ROMANOWSKI, Joana Paulin. Concepções de professores sobre a disciplina de Psicologia da Educação na formação docente. UNIrevista, v.1, n.2., abril/2006.

BONILLA, Maria Helena Silveira; PRETTO, Nelson De Lucca. Inclusão digital polêmica contemporânea. Salvador: EDUFBA, 2011, v.2.

BRAGA, Mauro Mendes. A licenciatura no Brasil: um breve histórico sobre o período 1973-1987. Ciência \& Cultura, São Paulo, v. 40, n. 2, 1988, p. 16-27.

CANDAU, Vera Maria Ferrão (Org). Novos rumos da licenciatura. Brasília, DF: INEP/ PUC-RJ, 1987. 
CARVALHO, Diana Carvalho de. As contribuições da psicologia para a formação de professores: algumas questões para debate. MARASCHIN, Cleci; FREITAS, Lia Beatriz de Lucca; CARVALHO, Diana Carvalho de (Orgs). Psicologia e educação, multiversos sentidos, olhares e experiências. Porto Alegre, Editora da UFRGS, 2003, p. 79-96.

CHAMPANGNATTE, Dostoiévski Mariatt de Oliveira; NUNES, Lina Cardoso. A inserção das mídias audiovisuais no contexto escolar. Educação em Revista, v.27, n.03, p.15-38, Belo Horizonte, dez/ 2011.

CHARLOT, Bernard. O professor na sociedade contemporânea: um trabalhador da contradição. Educação e Contemporaneidade, Salvador, v. 17, n. 30, p. 1-248, jul./ dez., 2008.

COLL, Cesar; MAURI, Teresa; ONRUBIA, Javier. A incorporação das tecnologias da informação e da comunicação na educação. COLL, Cesar; MONEREO, Carles (Orgs). Psicologia da educação virtual - aprender e ensinar com as tecnologias da informação e da comunicação. Porto Alegre: Artmed, 2010, p. 63-93.

COLL, Cesar; MONEREO, Carles (Orgs). Psicologia da educação virtual - aprender e ensinar com as tecnologias da informação e da comunicação. Porto Alegre: Artmed, 2010.

GATTI, Bernadete Angelina. Formação de professores no Brasil: características e problemas. Educação e Sociedade, Campinas, v. 31, n. 113, p. 1355-1379, out.dez. 2010.

GIOVANETTI, José Paulo. O sagrado e a experiência religiosa na psicoterapia. MASSIMI, Marina; MAFHOUD, Miguel (Orgs). Diante do mistério - psicologia e senso religioso. São Paulo: Ed.Loyola, 1999, p.87-96.

GIOVANETTI, José Paulo. A vivência religiosa no mundo (pós) moderno. Belo Horizonte: UFMG/FAFICH, 2000, 13p., (mimeo).

HUSSERL, Edmund. A crise da humanidade européia e a filosofia. 2. Ed. Porto Alegre: EDIPUCRS, 1897/2001.

LAROCCA, Priscila. O saber psicológico e a docência. Psicologia, Ciência e Profissão, 20 (2), 2000, p.60-65.

LAROCCA, Priscila. Problematizando os contínuos desafios da psicologia na formação docente. AZZI, Roberta Gurgel; SADALLA, Ana Maria Falcão de Aragão (Orgs). Psicologia e formação docente: desafios e conversas. São Paulo: Casa do Psicólogo, 2002, pp. 29-45. 
LAROCCA, Priscila. O ensino de psicologia no espaço das licenciaturas. ETD Educação Temática Digital, Campinas, v.8, n.2, p.295-306, jun/2007.

LEMOS, André. Prefácio. BONILLA, Maria Helena Silveira; PRETTO, Nelson De Lucca. Inclusão digital - polêmica contemporânea. Salvador: EDUFBA, 2011, v.2, pp. 15-22.

LUCION, Cibele da Silva; FROTA, Paulo Rômulo de O. Psicologia da Educação: contribuições para a formação docente em Ciências Naturais. Vidya, v.29, n.2, p. 31-42, jul-dez. 2009, Santa Maria.

MAFHOUD, Miguel (Org). Diante do mistério - Psicologia e senso religioso. São Paulo: Ed. Loyola, 1999. p.57-68.

MARQUES, Carlos Alberto; DINIZ-PEREIRA, Júlio Emílio. Fóruns das licenciaturas em universidades brasileiras: construindo alternativas para a formação inicial de professores. Educação e Sociedade, v. 23, n. 78, Campinas, 2002, p. 171-183. Disponível em: http://www.scielo.br/scielo.php?script=sci arttext\&pid=S0101-733. Acesso em: 10 nov. 2010.

MARQUES, Mário Osório. A reconstrução dos cursos de formação do profissional da educação. Em Aberto, Brasília, DF, n. 54, 1992, p. 7-18.

PARECER CNE/CES n. 266. Aprova os Referenciais Orientadores para Bacharelados Interdisciplinares e similares, Brasília, MEC, 2011, Disponível em www.portal.mec.gov.br

RAPOSO, Mírian Barbosa Tavares; MACIEL, Diva Maria Moraes Albuquerque. A psicologia e a formação docente: uma contribuição do sociocultural-construtivismo. Linhas Críticas, Brasília, v. 12, n. 22, p. 91-108, jan./jun. 2006

REFERENCIAIS ORIENTADORES PARA OS BACHARELADOS INTERDISCIPLINARES E SIMILARES. Fornece subsídios e estabelece bases para fins de avaliação e reconhecimento dos cursos. Brasília, MEC, 2010, Disponível em: www.portal.mec.gov.br

SOARES, Ademilson de Sousa. A formação do professor da Educação Básica entre políticas públicas e pesquisas educacionais: uma experiência no Vale do Jequitinhonha em Minas Gerais. Ensaio: aval. pol. públ. Educ., Rio de Janeiro, v.22, n. 83, p. 443-464, abr./jun, 2014.

SOUZA, João Valdir Alves (Org). Formação de professores para a educação básica: dez anos de LDB. Belo Horizonte: Autêntica, 2007.

SILVA, Laíssa Muniz; FACCI, Marilda Gonçalves Dias; SILVA, Rosane Gumieiro 
Dias. Teorias psicológicas e o trabalho do professor: análise em periódicos a partir da psicologia histórico-cultural. InterMeio, v. 14, n. 27, p. 74-87, jan.-jun, 2008.

TARDIF, Maurice; LESSARD, Claude. O trabalho docente: elementos para uma teoria da docência como profissão de interações humanas. Petrópolis: Vozes, 2005.

UNIVERSIDADE FEDERAL DOS VALES DO JEQUITINHONHA E MUCURI (2011). Projeto Político Pedagógico, Bacharelado em Humanidades, retirado de http:// www.ufvjm.edu.br/cursos/bhu/projeto-pedago-menubhu-753.html. Acesso em: $16 \mathrm{dez}$. 2013.

VIEIRA, Rita de Cássia; ASSIS, Raquel Martins; CAMPOS, Regina Helena de Freitas. Aprender e conhecer o outro: pensando o ensino de psicologia para educadores. Psicologia e Sociedade, v. 25, n.2, 2013, p. 399-409.

VIEIRA, Rita de Cássia; FIGUEIREDO, Ellen Rose Fernandes; SOUZA, Laís Gonçalves; FENNER, Marina Castana. A psicologia da educação nos cursos de psicologia de Belo Horizonte/Minas Gerais. Psicologia Escolar e Educacional, v. .17, n.2, jul-dez/2013, p. 239-248.

WOJTYLA, Karol. Persona e atto. Vaticano: Ed. Vaticana, 1982.

Recebido em setembro de 2015

Aprovado em dezembro de 2015

Rita de Cássia Vieira é doutora em Educação pela Universidade Federal de Minas Gerais (UFMG) e professora da Universidade Federal dos Vales do Jequitinhonha e Mucuri (UFVJM) e docente colaboradora no curso de Pedagogia a distância/UAB da Universidade Federal de Ouro Preto (UFOP). E-mail: rita.vieira@yahoo.com.br

Daniela Marx Damascena é graduanda Interdisciplinar em Humanidades pela Universidade Federal dos Vales do Jequitinhonha e Mucuri (UFVJM). Tem experiência na área de Psicologia, com ênfase em Psicologia do Desenvolvimento Humano. E-mail: dany.marx@gmail.com 